Article

\title{
A Black Swan in a Sea of White Noise: Using Technology-Enhanced Learning to Afford Educational Inclusivity for Learners with Asperger's Syndrome
}

\author{
James McDowell \\ Department of Informatics, University of Huddersfield, Huddersfield, HD1 3DH, UK; E-Mail: j.b.mcdowell@hud.ac.uk
}

Submitted: 23 August 2015 | In Revised Form: 29 November 2015 | Accepted: 9 December 2015 |

Published: 28 December 2015

\begin{abstract}
Against a backdrop of increasingly vocation-focussed course provision within higher education, of widening participation initiatives intended to promote greater inclusion for learners affected by learning difficulties, and of moves towards greater use of social and collaborative forms of learning, this paper discusses the case of an undergraduate Computing student affected by Asperger's Syndrome (AS).While there is recognition in the literature of problems associated with face-to-face dialogue for persons affected by AS, there is a paucity of research both into the experience of students in higher education, and around the issue of participation in group-work activities increasingly found in creative aspects of computing. This paper highlights a tension between moves towards collaborative learning and UK disabilities legislation in relation to learners with AS. Employing a qualitative case-study methodology, the investigation revealed how a technology-enhanced learning intervention afforded an AS-diagnosed learner greater opportunities to participate in groupwork in a higher education context. The findings suggest that not only can computer-mediated communications afford AS-diagnosed learners opportunities to participate meaningfully in group-work, but also that the learner demonstrated higher levels of collective-inclusive versus individual-exclusive phraseology than neurotypical peers, thereby challenging assumptions around participation in collaborative learning activities and assimilation of peer-feedback.
\end{abstract}

\section{Keywords}

Asperger's Syndrome; autistic spectrum; computer-mediated communication; collaborative learning;

technology-enhanced learning

Issue

This article is part of the special issue "Inclusive Technologies and Learning", edited by Don Passey (Department of Educational Research, Lancaster University, UK).

(C) 2015 by the author; licensee Cogitatio (Lisbon, Portugal). This article is licensed under a Creative Commons Attribution 4.0 International License (CC BY).

\section{Background and Context}

The prevalence of an autistic spectrum condition within the UK is estimated at c.1\% of the population (Baron-Cohen et al., 2009), and the incidence of students declaring an autistic spectrum disorder on entry to university is $1.1 \%$ (National Autistic Society, 2010). Within the cohort of students starting programmes of study at UK higher education institutions (UKHEIs) in the 2013-14 academic year, some 77,795 reported a disability on entry (HESA, 2015), of whom 2,415 students declared prior diagnosis of an autistic spectrum condition (ASC) at enrolment.

A Computing department at a UKHEI offering a range of degree programmes found that certain courses regularly attracted a higher than average proportion of learners declaring a known learning difficulty at the start of their studies; specifically, within the computer games cluster of courses, there was an established history of learners reporting a prior clinical diagnosis of an ASC such as Asperger's Syndrome (AS) at initial registration, with an incidence of between $3 \%$ to $5 \%$ of the 
cohort being common.

Learners affected by AS typically experience problems with face-to-face interaction and are unable to read social cues (Attwood, 2000). Previous research has identified group-work as being particularly problematic for these learners (MacLeod \& Green, 2009), however one objective of the computer games degree courses is to prepare learners to enter the games industry, and it is a stated requirement of the programme specification that students should work in small teams to develop a range of computer games.

This case-study formed a strand of a 12-month project which aimed to encourage the formation of a community of practice for learners studying on computer games pathways, using the Mahara e-portfolio system as a central focal point to facilitate a blended collaborative learning environment. Given the frequency of learners with AS in the participant group, this strand of that project aimed to address the special educational needs of these learners in relation to the role that they would play as collaborative learners. The findings of this study were therefore also intended to inform refinements to the Mahara e-portfolio system.

A significant factor impeding the educational success of learners with AS is an inability to recognise and respond to those social cues that make up much of face-to-face (F2F) verbal communications (Attwood, 2000). In recognition of the status of AS as a pervasive developmental disorder, the Special Educational Needs and Disability Act (HMSO, 2001), the Disabilities Discrimination Act (HMSO, 2005) and the Equality Act (HMSO, 2010) all require that learners affected by an ASC should be afforded the opportunity to undertake alternative forms of assessment, placing a duty of care on the institution to ensure that "disabled students are not placed at a substantial disadvantage in comparison with students who are not disabled" (HMSO, 2001, chapter 10). Where courses in subjects such as computer games seek to develop students' skills in groupwork, there is an inherent tension between the pedagogical requirements of courses that seek to meet the needs of the profession for which learners are being prepared, and the legislative requirements designed to protect and assist students with disabilities such as AS.

With the Mahara e-portfolio system in place to facilitate collaborative group-work, this strand of the project therefore sought to transcend the problem above by exploring how computer-mediated communications (CMCs) might afford greater educational inclusivity and improved social opportunity to AS learners who would otherwise find themselves disadvantaged by the focus on collaborative styles of social learning.

\section{Literature Review}

Asperger's Syndrome, first identified by Hans Asperger in 1948, is located in the spectrum of autistic condi- tions and is characterised by a triad of impairments (Wing \& Gould, 1979), comprised of problems with social interaction, communication and imagination (Attwood, 2000). While people affected by ASCs occupy all levels on the intelligence quotient scale, individuals with AS have an "overall IQ usually within the normal or above normal range" (Klin \& Volkmar, 2000, p. 342) and are often highly aware of the difficulty they experience in communicating with others (Attwood, 2000; Benford, 2008). Being "unable to attribute mental states to others" (Benford, 2008, p. 32), individuals affected by AS will typically find F2F communication difficult, preferring to avoid eye contact and often responding to questions with very short, or even oneword, answers (Attwood, 2000).

A high sensory sensitivity, particularly to audio inputs (Attwood, 2000), can also make concentrating in noisy environments such as lecture theatres and studio-labs especially difficult, and coupled with the need to process and interpret the meaning of multiple voice inputs, AS-diagnosed students can be expected to find managing the requirement to understand and respond to the group dynamic in F2F contexts particularly problematic. Illustrative of the situation faced by many learners with AS, the case of Andrew, an academically capable undergraduate studying at a UKHEI, highlights the level of anxiety experienced by learners with AS when required to participate in group-work. In Andrew's case, despite holistic collaborative support being in place to help him cope with his studies, the pressure experienced when attempting to participate in F2F group-work ultimately led to this learner withdrawing from university altogether (MacLeod \& Green, 2009).

While the affinity of persons diagnosed with an ASC for using computers is well documented (e.g. Attwood, 2000; Murray, 1997), research into the use of computer-mediated communications by this group is still relatively new (e.g. Gillespie-Lynch, Kapp, Shane-Simpson, Smith, \& Hutman, 2014). One earlier investigation into the use of mobile phones by adolescents with AS found this group were significantly less likely to use the voice features of the technology than the text-messaging functionality, and would prefer to use the latter to communicate (Durkin, Whitehouse, Jaquet, Ziatas, \& Walker, 2010); these findings echo those noted elsewhere by an observed preference in AS individuals for written rather than voice communications in social media (Benford, 2008; Burke, Kraut, \& Williams, 2010).

There has been a proliferation of tools to promote and facilitate online collaborative working, and useful research has been undertaken in this area (e.g. An, Kim \& Kim, 2008; Curtis \& Lawson, 2001; McConnell, 2006). Although it has been noted that working collaboratively online can result in "missing social cues that can help one understand what is being communicated" (McConnell, 2006, p. 128), this loss is inverted for the AS-diagnosed learner, as "being more object focused 
than people focused is clearly only a disability in an environment that expects everyone to be social" (BaronCohen, 2002, p. 491).

Against this background, the use of technologyenhanced learning (TEL) interventions specifically to facilitate participation in group-work by learners with AS appeared to be an under-researched area. While there is evidence of some success in a single-case case-study of a 7-year old boy with autism using CMCs to interact with two classmates in a school situation (Lewis, Trushell, \& Woods, 2005), the significant differences in age and of disabilities support requirements between the schoolboy and university undergraduates make any comparisons contentious, and it therefore appeared that there was scope for further research in this area within a higher education context.

\subsection{Research Question}

In light of the gap in the literature identified above, the following research question was formulated:

How might a technology-enhanced learning intervention afford an AS-diagnosed learner in higher education greater opportunity to participate in group-work?

\section{Methodology, Methods and Research Design}

\subsection{Theoretical Lens and Methodological Approach}

This study is underpinned by an epistemological stance founded in the pragmatist tradition (Dewey, 1944). Located between the epistemological poles occupied by interpretivism and positivism, the pragmatist position is broadly consistent with case-study methodology (Saunders, Lewis, \& Thornhill, 2009), and this adoption of a pragmatist epistemology provided a basis from which to consider perspectives and predictions emerging through qualitative and/or quantitative approaches to data collection and analysis, initially by facilitating the collection of data using various methods and from a variety of sources, and later through highlighting a range of further research requiring work using both approaches.

Further, this epistemological position is supported by an ontological stance which embraced work from Bakunin (1916), Goodman (1962, 1964) and Illich $(1970,1971)$ that sought to foster the development of inclusive communities of learners; to this end, the theoretical framework against which the investigation was conducted can be viewed through the lens of an exploration of opportunities for digital inclusion, rather than with the objective of identifying where technologies could be made accessible (Seale, 2014). Finally, through being rooted in an approach to practice that actively sought to collapse teacher-student hierarchy (Bakunin,
1916; McDowell, 2010; Suissa, 2006), this investigation promoted a teacher-student relationship which remained uncomplicated by those issues of social hierarchy identified as giving rise to confusion and anxiety in AS-diagnosed persons (Attwood, 2000; Baron-Cohen, 2008; Higgins, Kocha, Boughfman, \& Vierstra, 2008).

\subsection{Characteristics of the Case-Study}

With the freedom to draw on methods and sources afforded by the adoption of a pragmatist epistemology, the investigation assumed a primarily qualitative approach to case-study, focusing on a single case of an undergraduate student diagnosed with Asperger's Syndrome working on a computer game development project in a group with three other students. None of these three students had made any previous declaration of a disability; while acknowledging that the absence of a declaration did not necessarily exclude the possibility that one or more of these students may have been affected by an undiagnosed or undeclared disability, neither the researcher's in-class observations nor the subsequent expert witness accounts suggested that these students displayed any behavioural patterns associated with AS, and the three students are therefore described as neurotypical throughout this study.

Framed as a first investigative iteration within a larger teaching and learning project, this case-study combined both exploratory and explanatory characteristics (Yin, 1993), insofar as it attempted both to determine whether a causal link existed between the use of a TEL intervention and successful participation in group-work by an AS-diagnosed student, and, if so, to investigate why this might be the case. Further to this, as the case itself was of primary interest for the purposes of assisting an individual affected by AS, it is an intrinsic case-study, however situated against the background of the larger project, it can also be viewed as an instrumental case-study, as the research was conducted with a view to gaining understanding of a broader picture (Stake, 1995).

An important criticism of case-study methodology is that of an inability to generalise from the findings. In contrast to a quantitative study, which might be expected to generate statistical data regarding the outcomes of an intervention, a single-case case-study generates data which is necessarily highly specific to that case, and without multiple cases available to facilitate data source triangulation, or multiple researchers to facilitate investigator triangulation, there is a possibility that a single researcher investigating a single case will provide only a narrow and subjective interpretation (Denzin, 1989). Stake counters this criticism, proposing that "naturalistic generalisation" (1995, p. 85) can emerge from a single-case case-study in the form of an intuitive generalisation made by the reader from their interpretation of the data presented by the researcher, 
wherein the reader's experience bears a correlative approximation to the account presented by the researcher.

A further argument for the strength of the singlecase case-study approach was derived from Popper's proposal that an observation of a single black swan falsifies the proposition 'all swans are white' (Popper, 1959), thereby imbuing the case with "general significance and stimulat[ing] further investigations" (Flyvbjerg, 2006, p. 228). Against this background, generalisations based on this investigation into the case of a single AS-diagnosed individual whose patterns of behaviour did not match those predicted by the literature and the expert witnesses were validated.

\subsection{Case Selection}

Selection of the case was determined by the availability and willingness to participate of both an AS-diagnosed undergraduate, to whom we refer here as Alex (name changed to preserve confidentiality), and other members of Alex's game development group; access to this group arose as the researcher was the module leader for the game development studio class, and had worked with the cohort in the previous academic year.

\subsection{Sources of Evidence}

Of Yin's (2003) six admissible sources of evidence in a case-study, four are used here: documentation, in the form of expert witness accounts; participant observation, of the interactions between the group members in a F2F context; direct observation, of the online interactions between them; and interviews, in the form of email interviews undertaken with the four learners. The two sources of evidence not used in this casestudy included archival records and physical artefacts, neither of which was manifest in any form within the scope of the investigation.

\subsection{Data Collection Procedures and Analysis Design}

As the four participants formed a single group working on a game development project, the three neurotypical-participants acted as a control group, allowing the researcher to compare and contrast Alex's responses with those of the neurotypical learners, thereby providing a source of evidence with which to triangulate the case, and to strengthen the internal validity of the case-study.

As a single case was investigated within this group of students, the unit of analysis employed was that of the individual. Expert witness accounts were generated through a series of open-ended interviews with three ASC professionals, both informing the strategy for the development of the case-study, and leading to a series of predictions (see Table 1) against which the findings would later be analysed. Both offline and online activities and interactions of the four participants were observed before proceeding to individual email interviews.

Data collection proceeded according to the following schedule:

1. First open-ended interview with Lecturer in Psychology whose specialism is in AS

2. Email interview with Alex's Disabilities Support worker, with follow-up questions

3. In-class observations of interaction between the four members of the group

4. Observation of interactions between group members within the e-portfolio system

5. Second open-ended interview with Lecturer in Psychology specialising in AS

6. Email interview with each studentparticipant, with follow-up questions

7. Final open-ended interviews with expert witnesses.

Expert witness accounts gathered during phases 1-2 helped to generate the series of predictions which informed the observational perspectives employed in phases 3 and 4, and a discussion of these observations with the expert witness in phase 5 helped to finalise the approach to the email interviews conducted in phase 6 . The data collected in phases 3 and 4 was analysed by employing a combination of pattern-matching against the predictions, with both constant comparative (Glaser \& Strauss, 1967) and direct interpretation (Stake, 1995) techniques. Results were triangulated with the data returned from phase 6 , which was analysed using the same strategy. Finally, rival interpretations of the findings were sought from the expert witnesses in phase 7 to help strengthen construct validity.

\subsubsection{Ethical Approval Process}

A two-stage ethical approval process was completed prior to the commencement of the study. As an investigation in which data would be collected from and about student participants, it was first necessary to gain general ethical approval before undertaking any data collection activities. Given that the focus of the case-study involved contact with an individual categorised as 'vulnerable', a second, higher level of ethical approval was subsequently sought in which it was necessary to confirm how the project satisfied four key ethical principles of non-maleficence, beneficence, autonomy and justice. This second stage required any potential power imbalances or dependent relationships between researcher and participants to be outlined, for assurances to be given that Alex's status as an AS-diagnosed individual would not be explicitly divulged to his peers, and that all research instruments used would be designed to avoid indirect disclosure of this information. 
In order to meet the requirements of the Data Protection Act (HMSO, 1998), it was necessary to confirm that the data would be stored securely, that all data would be anonymised, and that any participant wishing to see the data could make a subject access request of any data held on them.

\subsubsection{Participant Consent}

Student-participants were presented with a summary of the project and an explanation of how the data would be used, and informed of their right to withdraw their consent in a form that they were requested to sign before interviews could take place. In order to respect the confidentiality of Alex's diagnosis, two sentences referring to AS were removed from the consent documentation presented to the control-participants.

\subsection{Observations and Interviews}

Adopting an "unstructured" approach to observation (Cohen, Manion, \& Morrison, 2007, p. 397), the researcher conducted non-interventionist observations while running studio-sessions with the studentparticipants, primarily as direct-observer but occasionally as participant-observer. Observations were formalised immediately following studio sessions to help ensure authenticity and richness of data.

A range of literature (e.g. Attwood, 2000; BaronCohen, 2008; Benford, 2008) suggested that F2F interviews might not be an ideal approach to collecting data from an AS-diagnosed participant. Following the second consultation with the AS-specialist expert witness, and in line with the approach taken in Benford's (2008) study on internet use and autism, the researcher made the decision to conduct email interviews, such that interview questions were emailed to the four participants as a Microsoft Word document, with interview prompts replaced by follow-up questions.

A significant consideration in reaching this decision was that using a written form of interview meant that time pressures were eliminated from the process, allowing answers to the questions to be constructed at a pace, and to a level of detail, with which Alex felt comfortable. While one possible disadvantage was that there would be a delay in the arrival of any follow-up questions, the email interview strategy allowed all participants to retain a record of their responses, and their attention was refocused by placing these questions in the follow-up email immediately after the original responses. This also made it possible to analyse any significant differences in the written styles of the four participants, and thereby to directly address one of the predictions arising from the review of the literature and subsequent contact with the three expert witnesses.

\subsection{Analysis and Validity: Triangulation of Data}

Triangulation of the data broadly followed Denzin's (1989) model of methodological triangulation, wherein a range of data collection methods are applied-one followed by another-in order to ensure consistency of evidence obtained, thereby testing the validity of the predictions mentioned above. The researcher attempted a synthesis of Denzin's model with Yin's 'detective' approach (Yin, 2003); by referring the evidence arising back to the 'expert witness', the professionalparticipants were invited to offer rival interpretations (Yin, 2003) to help strengthen internal validity.

While the phrase triangulation implies the coordination of three lines of enquiry, this study used four sources of evidence, starting first with expert witness evidence from three separate parties, then F2F observation of in-class interactions within the group, followed by observation of online activity, and finally the email interview process. As each line of enquiry uncovered new data, this informed how subsequent lines of enquiry should progress in order to focus ever closer on the case.

The case-study was conducted within a relatively short time-frame, and the volume of data generated through the email interview process was sufficiently manageable to enable the researcher to proceed with analysis of the written responses of the studentparticipants using a hand-coding strategy. Focusing primarily on the use of collective versus individual phraseology in responses, the researcher was able to engage in triangulation with the predictions directly from the response texts employing the "constant comparative method" (Glaser \& Strauss, 1967, p. 101).

\section{Findings and Discussion}

It was initially noted from the observations made in the F2F studio-laboratory setting that Alex appeared to be finding the experience uncomfortable, and was playing only a limited role within the group; this might have been interpreted as suggesting that Alex would not cope with group-work, thereby confirming one of the predictions (see P1 in Table 1). An alternative perspective was that simply playing even a limited role indicated a significant degree of success on Alex's part, and this clearly contrasted with the experience of Andrew, the undergraduate student whose case was described by MacLeod and Green (2009).

Subsequent observation of the group's online activity however, revealed that Alex was not only communicating with other group members via the blogging and discussion forum features, but had taken the lead in getting the group's online activities underway, as indicated by Alex's creation of the first discussion forum area in which the opening post was: 
Alex: "I guess we should probably pitch ideas and things here?"

Further evidence found in the e-portfolio system indicated that Alex had posted ideas of how to take the project forward, had left feedback on others' ideas, such as "Hey, that's great!", and had uploaded concept artwork and other materials to which feedback was requested from other members of the group, asking "What do you think?".

This cluster of observations ran contrary to a key prediction (P6) of how Alex might be expected to respond to feedback from peers (Benford, 2008; Twachtman-Cullen, 1998; National Autistic Society, 2010), and when this evidence was presented for rival interpretation, the expert witnesses confirmed this particular behaviour as highly unusual, leading one to suggest that this could be of great potential significance to the AS-research communi- ty, and worthy of further investigation.

A comparative analysis of the use of collectiveinclusive phraseology in responses to the first email interview question, "Please describe how you have used Mahara in the...module", suggested that Alex appeared to value the facilitation of group-work afforded by the intervention, in common with the neurotypicalparticipants (NP):

Alex: "I've used it to keep in touch with other members of the group, and share work and information regarding our project".

NP 3: "I have used Mahara to upload work I have done so that the rest of the team could access it, I have also used it to talk to the other members of the group and find out what we are all doing."

Table 1. Illustrating the predictions, sources of evidence analysed, and correlation between predictions and evidence.

\begin{tabular}{ll}
\hline Predictions & Source of Evidence \\
\hline P1. Alex will be unable to participate & Literature Review, Expert \\
meaningfully in group work & Witnesses, F2F Observation, \\
& Observation of Online \\
& Activity, Email Interviews
\end{tabular}

P2. Alex will experience difficulties dealing with social cues in F2F group situations

P3. Alex's written word will be more eloquently expressed than spoken word

P4. Alex will display anxiety and nervousness in F2F group situations

Literature Review, Expert Witnesses, F2F Observation

Literature Review, Expert Witnesses, F2F Observation, Observation of Online Activity, Email Interviews Literature Review, Expert Witnesses, F2F Observation
P5. Alex will not take the initiative in group-work

P6. Alex will not engage in the process of offering and requesting feedback from other group members
Literature Review, Expert Witnesses, F2F Observation, Observation of Online Activity, Email Interviews

Expert Witnesses, F2F Observation, Observation of Online Activity Pattern-Match or Correlation of Sources

Negative - according to literature and expert witnesses, Alex should have been unable to cope with group work, however observations and email interviews contradict this.

Positive - according to literature and expert witnesses, Alex should experience difficulty in dealing with social cues, and observations of Alex in F2F situations confirmed this.

Positive - all sources confirm that Alex demonstrates greater eloquence in written communications than in spoken and F2F situations.

Neutral - Alex initially displayed high levels of nervous behaviour in F2F situations, as predicted by the literature and expert witnesses, however later F2F observations suggested improvement in this area, with signs of diminishing anxiety and increasing confidence in participation.

Negative - according to the literature and expert witnesses, Alex should not take a lead in F2F group-work, however online and email sources indicate that the student has done so in non-F2F contexts, initiating new discussion threads and posting ideas for consideration by other group members

Negative - expert witness evidence suggests feedback is particularly difficult for learners with AS, however F2F observations indicate some success in overcoming this, and online observations highlight pro-activity in both offering feedback and requesting it. 
While these responses indicate a commonality between the experience of Alex and that of the neurotypical-participants, the former's use of collectiveinclusive syntax ran contrary to two important predictions (P1 and P5).

An analysis of the frequency of collective-inclusive versus individual-exclusive phraseology used in responses to the question, "Please describe how using Mahara has affected the way you have approached your work in the...module", suggested that Alex had engaged with and felt a part of the group, as indicated by the response:

Alex: "It's helped us to share files more frequently and easily than we could have otherwise done, without it, we'd probably have to send large emails or pass around pen drives all the time to keep everyone up to date, whereas with Mahara we can get the files to each other and update them a lot easier." (author's emphasis)

By contrast, the neurotypical-participants made greater use of individual-exclusive phraseology in their responses to the same question, as illustrated below:

NP 1: "It has had a fairly significant effect. Having to blog every week both refreshes the memory of what has been previously written and makes me think "What have I done this week and what will I do next week?"

NP 2: "The main effect of using Mahara is that it alleviates some of the pressure of the course by reducing the volume of written work we have to do, which I have always considered to be one of $\mathbf{m y}$ weaknesses."

The findings above were derived from a case-study which has examined a single case of an AS-diagnosed undergraduate student. While it is recognised that a diagnosis implies certain common characteristics, it should be noted that each AS-diagnosed person is an individual with their own learning preferences, and that there can be no one-size-fits-all intervention which acts as a panacea (Twachtman-Cullen, 1998).

\subsection{Further Research}

The findings of this study would be strengthened further, and the validity of the single-case extended, if this research could be repeated with multiple cases, encompassing AS-diagnosed students at a range of institutions, and the research conducted by multiple researchers, thereby enabling alternative interpretations to be sought. Further to this, adopting a mixed methods approach and incorporating a quantitative longitudinal study designed to measure the impact of the in- tervention on academic achievement might also enhance the usability of these findings.

\section{Conclusions}

This investigation examined a key tension between pedagogy and legislation in the context of students with Asperger's Syndrome, and explored a TEL-based solution to the problem of enabling students with an ASC diagnosis to participate in group-work and to engage in collaborative learning. Although this investigation has built upon and extended the reach of previous research in overlapping fields, approaching the problem by introducing a TEL intervention appears to break new ground in this area.

The findings of the research suggested that by enabling group-work to take place both offline and online through the use of CMC tools such as e-portfolio systems which are commonly used in TEL settings, students with an AS diagnosis might be afforded greater opportunity to play an integral role as part of a team working on a group project as part of a course of study within higher education. As a result, academicallycapable learners who might otherwise have found themselves unable to complete a course of study might be facilitated opportunities to work alongside neurotypical colleagues, and enabled both to more completely fulfil their potential, and to make the transition from study environment to workplace.

While this intervention appears to have application for the development of guidance for professionals working with individuals diagnosed with AS, and to inform best practice within the HE sector as an inclusive strategy to transcend the tension between contemporary pedagogical practice and current legislative requirements, the implications for the wider world of work through embracing this approach have the potential to dwarf those of universities and colleges. As industry and commerce embrace social learning and online collaborative working practices, it is possible that a TEL intervention could enable unemployed and underemployed AS-diagnosed individuals to use their unique talents and special expertise to become increasingly economically productive, and to experience greater inclusivity within society as a whole.

\section{Conflict of Interests}

The author declares no conflict of interest.

\section{References}

An, H., Kim, S., \& Kim, B. (2008). Teacher perspectives on online collaborative learning: Factors perceived as facilitating and impeding successful online group work. Retrieved from http://www.citejournal.org/articles/ v8i1general1.pdf 
Attwood, T. (2000). Asperger's Syndrome: A guide for parents and professionals. London and Philadelphia: Jessica Kingsley.

Bakunin, M. (1916). God and the State. Retrieved from http://dwardmac.pitzer.edu/Anarchist_archives/bak unin/godandstate/godandstate_ch1.html

Baron-Cohen, S. (2002). Is Asperger Syndrome necessariIy viewed as a disability? Focus on Autism and Other Developmental Disabilities, 17(3), 186-191.

Baron-Cohen, S. (2008). Autism and Asperger's Syndrome. Oxford: Oxford University Press.

Baron-Cohen, S., Scott, F. J., Allison, C., Williams, J., Bolton, P., Matthews, F. E., \& Brayne, C. (2009). Prevalence of autism-spectrum conditions: UK schoolbased population study. The British Journal of Psychiatry, 194(6), 500-509.

Benford, P. (2008). The use of Internet-based communication by people with autism (PhD thesis). Nottingham: University of Nottingham. Retrieved from http://etheses.nottingham.ac.uk/661

Burke, M. J., Kraut, R. E., \& Williams, D. (2010). Social use of computer-mediated communication by adults on the autism spectrum. In CSCW 2010: Proceedings of the ACM Conference on Computer-Supported Cooperative Work. New York: ACM Press. Retrieved from http://www.thoughtcrumbs.com/publications/ Burke_CSCW2010_CMC_and_Autism.pdf

Cohen, L., Manion, L., \& Morrison, K. (2007). Research methods in education ( $6^{\text {th }}$ edition). Abingdon and New York: Routledge.

Curtis, D. D., \& Lawson, M. J. (2001). Exploring collaborative online learning. Journal of Asynchronous Learning Networks, 5(1), 21-34.

Denzin, N. K. (1989). The Research Act: A theoretical introduction to sociological methods. Englewood Cliffs: Prentice-Hall.

Dewey, J. (1944). Democracy and education. New York: Free Press.

Durkin, K., Whitehouse, A., Jaquet, E., Ziatas, K., \& Walker, A. J. (2010). Cell phone use by adolescents with Asperger Syndrome. Research in Autism Spectrum Disorders, 4(2), 314-318.

Flyvbjerg, B. (2006). Five misunderstandings about casestudy research. Qualitative Inquiry, 12(2), 219-245.

Gillespie-Lynch, K., Kapp, S. K., Shane-Simpson, C., Smith, D. S., \& Hutman, T. (2014). Intersections between the autism spectrum and the internet: Perceived benefits and preferred functions of computermediated communication. Intellectual and Developmental Disabilities, 52(6), 456-469.

Glaser, B. G., \& Strauss, A. L. (1967). The discovery of grounded theory: Strategies for qualitative research. New York: Aldine Publishing Company.

Goodman, P. (1962). The community of scholars. New York: Random House.

Goodman, P. (1964). Compulsory mis-education. New York: Horizon Press.
Higher Education Statistics Agency [HESA]. (2015). Students, qualifiers and staff data tables. Retrieved from https://www.hesa.ac.uk/content/view/1973/239

Higgins, K., Kocha, L., Boughfman, E. M., \& Vierstra, C. (2008). School-to-work transition and Asperger Syndrome. Work, 31(3), 291-298.

HMSO. (1998). The Data Protection Act. Retrieved from http://www.legislation.gov.uk/ukpga/1998/29/conte nts

HMSO. (2001). The Special Educational Needs and Disabilities Act. Retrieved from http://www.legislation. gov.uk/ukpga/2001/10/pdfs/ukpga_20010010_en.p df

HMSO. (2005). The Disabilities Discrimination Act. Retrieved from http://www.legislation.gov.uk/ukpga/ 2005/13/pdfs/ukpga_20050013_en.pdf

HMSO. (2010). The Equality Act. London. Retrieved from http://www.legislation.gov.uk/ukpga/2010/15/pdfs/ ukpga_20100015_en.pdf

Illich, I. (1970). Celebration of awareness: Call for institutional revolution. Garden City, NY: Doubleday.

Illich, I. (1971). Deschooling society. London: Calder \& Boyars.

Klin, A., \& Volkmar F. R. (2000). Treatment and intervention guidelines for individuals with Asperger's Syndrome. In A. Klin, F. R. Volkmar \& S. Sparrow (Eds.), Asperger Syndrome (pp. 340-366). New York: Guildford Press.

Lewis, L., Trushell, J., \& Woods, P. (2005). Effect of ICT group work on interactions and social acceptance of a primary pupil with Asperger's Syndrome. British Journal of Educational Technology, 36(5), 739-755.

MacLeod, A., \& Green, S. (2009). Beyond the books: Case study of a collaborative and holistic support model for university students with Asperger syndrome. Studies in Higher Education, 34(6), 631-646.

McConnell, D. (2006). E-Learning groups and communities. Berkshire: Open University Press.

McDowell, J. (2010). Anarchy in the universities: Beyond the student-teacher hierarchy. Paper presented at the Learning Futures Festival 2010, University of Leicester, 14 ${ }^{\text {th }}$ January 2010.

Murray, D. K. S. (1997). Autism and information technology: Therapy with computers. In S. Powell \& R. Jordan (Eds.), Autism and learning: A guide to good practice. London: David Fulton.

National Autistic Society. (2010). Guidelines for teaching students with Asperger syndrome in further education colleges. Retrieved from http://www.nas.org. uk/nas/jsp/polopoly.jsp?d=1011\&a=15419

Popper, K. (1959). The logic of scientific discovery. New York: Basic Books.

Saunders, M., Lewis, P., \& Thornhill, A. (2009). Research methods for business students (4th ed.). Essex: Pearson.

Seale, J. K. (2014). E-learning and disability in higher education (2nd ed.). Abingdon and New York: Routledge. 
Stake, R. (1995). The art of case research. Newbury Park, CA: Sage Publications.

Suissa, J. (2006). Anarchism and education: A philosophical perspective. Milton Park: Routledge.

Twachtman-Cullen, D. (1998). Language and communication in high-functioning autism and Asperger Syndrome. In E. Schopler, G. B. Mesibov, \& L. J. Kunce (Eds.), Asperger Syndrome or high-functioning autism? (pp. 199-225). New York: Plenum Press.
Wing, L., \& Gould, J. (1979). Severe impairments of social interaction and associated abnormalities in children: Epidemiology and classification. Journal of Autism \& Developmental Disorders, 9(1), 11-29.

Yin, R. K. (1993). Applications of case study research. Newbury Park, CA: Sage Publishing.

Yin, R. K. (2003). Case study research: Design and methods (3rd ed.). Thousand Oaks, CA: Sage Publishing.

\section{About the Author}

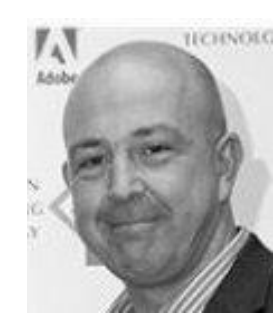

\section{Dr. James McDowell}

James McDowell is Director of Teaching and Learning in the School of Computing and Engineering at the University of Huddersfield. An award-winning researcher-practitioner in the field of technologyenhanced learning, James pursues a range of research interests including video-enhanced learning, assessment and feedback, the use of mobile communications technologies to aid spatial orientation for visual impairment, games-based learning to overcome sensory issues for children affected by autistic spectrum conditions, and the use of the brain-computer interface in virtual environments. 